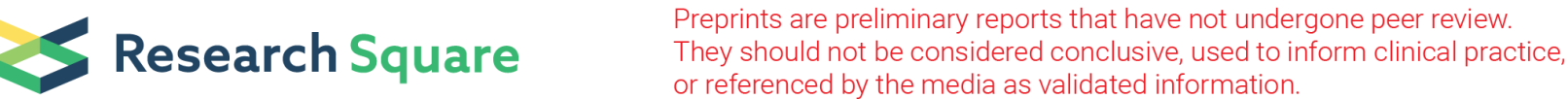

\section{Development and psychometric evaluation of a scale on nursing students' perceptions of hospital caring environment (PHCE) in China}

li cheng

Hubei University of Medicine https://orcid.org/0000-0003-0242-4133

Yilan Liu (D53108690@qq.com )

Wenru Wang

National University of Singapore

Research article

Keywords: nursing education, caring environment, perception, clinical, instrument

Posted Date: November 19th, 2019

DOI: https://doi.org/10.21203/rs.2.17421/v1

License: (c) (i) This work is licensed under a Creative Commons Attribution 4.0 International License.

Read Full License 


\section{Abstract}

Background : Caring is a basic tenet of nursing and an essential trait a competent nurse. In China, nursing students spend 8-12 months on clinical rotation in hospitals after the completion of theoretical component of the program in their fourth year. The hospital then becomes the focus of nursing clinical education. However, there is no culturally-specific tool to assess nursing students' perceptions of hospital caring environment (PHCE). The aim of this study was to develop a valid assessment tool to measure nursing students' perceptions of hospital caring environment.

Methods: A two-phase study was conducted to develop a PHCE scale and to test its psychometric properties. In phase one, the items of the PHCE scale were developed from a qualitative study, a literature review and expert validation. The second phase tested the factor structure, construct validity and reliability through a convenience sample of 383 final year nursing students recruited from two teaching hospitals in China (response rate 95.75\%).

Results: The final PHCE scale consists of 41 items, was internally consistent (Cronbach's a $=0.98$ ) and had satisfactory test-retest reliability (intra-class correlation coefficient $=0.87$ ). The exploratory factor analysis revealed that the scale contained four subscales, accounting for $63.69 \%$ variance.

Conclusions: The 41-item NSPHCE is a reliable tool to assess the Chinese nursing students' perceptions of the hospital caring environment in China.

\section{Background}

The concept of care has been associated with nursing since the Nightingale era. Willis, Grace and Roy [] defined professional nursing as "a health care discipline and healing profession, both an art and science, which facilitates and empowers human beings in envisioning and fulfilling health and healing through the application of nursing knowledge and practice" ( $p 33$ ). Nursing is a practice-oriented discipline [], a caring profession that deals with human conditions and their responses to health and illness [], and thus, caring is the basic tenet of nursing, and it is the profession's core competency []. Sister Roach [] focused on caring as the most common authentic criterion of humanness and proposed the five Cs of caring that each of the health care professions need: compassion, competence, confidence, conscience and commitment. In short, caring is a critical component of nursing, a valued attribute of a professional nurse ].

A culture of caring in a teaching and learning environment is important to strengthen nursing students' learning [. The 18th article of the new Nurse Regulation of People's Republic of China (PRC), published in 2008 , clearly defined that nurses should respect, show concern and care for the patients. Caring ability becomes an important attribute of a competent nurse. Therefore, a core value of nursing education and practice of both the National League of Nursing (NLN) and the American Association of Colleges of Nursing (AACN) is caring []. 
Caring ability is related to a caring school environment. Hughes [ developed an instrument named the Peer Group Caring Interaction Scale (PGCIS) in 1998 and found that students' peer interactions are more caring when they experience caring. The caring experience also helped students to offer care to their patients. Simmons and Cavanaugh's [ study suggested that a caring school environment is the strongest predictor of nursing students' caring ability. The participants in a caring group were found to possess a higher level of awareness of the meaning and importance of caring, acceptance of others and appreciation of caring and self-care [. Nurses involved in facilitating students' learning must adopt a compassionate caring attitude, which is an important condition in the students' skills' development [. Pai, Eng and Ko [ reported that nursing education should encompass building caring behaviours into the curriculum so a student can utilise these behaviours when caring for their patients. Some studies conducted with Chinese nursing students also reported that the atmosphere of the learning environment, clinical instructors' modelling and the experiences of clinical practice are the influencing factors in developing a student's caring ability [].

The clinical setting is the most influential environment for knowledge acquisition and professional nursing skills development in nursing students []. Papastavrou et al. [ suggested that a thorough examination and understanding of the clinical environment as a conducive place for learning is needed. During a time-limited clinical experience, the most important role model can be demonstrated by one-toone contact with a clinical instructor, including a one-to-one relationship with a registered nurse (RN) and a nursing student and the behaviours of the RN toward patients [. At the same time, students may develop moral judgments and values from interactions with their peers [. According to Beck [,], when nursing students cared for one another, they learned caring and shared their clinical experiences with one another. Such sharing of experiences was found to facilitate learning practical caring ways in dealing with patients.

Clinical learning is a crucial component of nursing education []. Clinical teachers modelling caring behaviours can facilitate nursing students' clinical learning []. Clinical teachers should also provide leadership as part of their teaching role in facilitating students' learning $\mathrm{\square}$. It has been found that other health care professionals in the hospital can also play an important part in students' learning. University clinical facilitators should collaborate with clinical nurses and other health care professionals to meet students' learning objectives []. If clinical teachers cannot model caring behaviours, students may not be able to provide caring behaviours to their patients. A cross-sectional study by Loke, et al. [ in Singapore among pre-registration nursing students using the Caring Behaviour Inventory showed a statistically significant reduction in the caring behaviours of students from the first to final year, and they highlighted the need to develop student nurses' caring attitudes throughout their educational journey [27].

Caring is a basic tenet of nursing and an essential trait of a competent nurse. In China, nursing students normally spend their entire final year at their clinical posting at hospitals to prepare them to be registered nurses. The hospitals are the focus of clinical nursing education and the most influential setting in the development of caring. Where does the caring environment come from during the clinical learning? Whose care can be perceived by nursing students? There are clinical instructors, nursing peers and other 
health care workers besides the nursing students in hospitals. Understanding nursing students' perceptions of caring in hospital would help the nursing educators to address their concerns and help the educators to develop the students' caring abilities. The literature review found no culturally specific instrument being developed to assess nursing students' perceptions of caring in hospitals in China. Therefore, the purpose of this study was to develop a scale to measure nursing students' perceptions of the caring environment in hospital in China and evaluate its psychometric properties.

\section{Method}

\section{Development of the Nursing Students' Perceptions of Hospital Caring Environment (PHCE) Scale}

The first phase of the study was to develop the instrument item pool. An exploratory qualitative approach using face-to-face interviews was adopted to explore nursing students' perceptions, experiences, feelings of caring and the most unforgettable caring events they had observed during nursing clinical practice in hospitals. A total of 14 nursing students were interviewed using an open-ended interview guideline. The main interview questions included: 'How do you think about caring?', 'Which behaviours do you think are caring in a hospital?', 'What kinds of caring behaviour did you observe when you practised in a hospital?', and 'What was your most unforgettable caring event in a hospital'? The interviews were conducted at a teaching hospital in Wuhan, China. Each interview lasted approximately 30 to 45 minutes. The interviews were immediately transcribed verbatim, and content analysis was conducted to analyse the data.

Seventy-four meaningful descriptions of nursing students' perceptions of the hospital caring environment were extracted and form the initial items of the PHCE scale. Four themes emerged from the qualitative data analysis: (1) perceptions of caring form clinical instructors' caring behaviours for patients, (2) perceptions of caring form clinical instructors' caring behaviour for the nursing students, (3) perceptions of caring from peers, and (4) the perceptions of caring from the other health care workers in the wards.

The initial version of the PHCE scale consisted of 74 items, grouped under four domains: clinical instructors' caring behaviour for patients, clinical instructors' caring behaviour for students, caring from the peers and caring from the other health care workers. Eight final-year nursing student and seven clinical nursing teachers were invited to evaluate the PHCE on its validity in assessing nursing students' perceptions of hospital caring environment and to examine the clarity of the instrument. Three round consultations were conducted for consensus, and a total of a 62-item PHCE was established after the initial round.

A panel of seven content experts, including two nursing educators, three nurse managers and two clinical nurse teachers, were then recruited to evaluate the content validity of the PHCE scale for content relevance. Using a 4-point Likert scale: $1=$ not relevant, $2=$ somewhat relevant, $3=$ relevant and $4=$ very relevant, the content experts rated whether each item was clear, appropriate, accurate and contentrelevant. A plausible method of estimating the content validity of a new scale is using the content validity Index (CVI) [. In the first course of content validity testing, four items with item-CVI $<0.75$ were removed 
as the CVI suggested that they were similar to the other items. Two other items were revised to minimize confusion. The revised instrument was then sent to the content experts for another course of content validation. After removing four items due to low item-level CVI, a 58-item PHCE scale was developed as shown in Table 1. The total CVI of the 58-item PHCE scale was 0.93 .

\section{Insert Table 1 58-item of PHCE here}

\section{Psychometric Testing Procedure}

To evaluate the psychometric properties of the PHCE scale, namely, the factor structure, internal consistency and test-retest reliability, a convenience sample of 400 final-year nursing students were recruited from two teaching hospitals at the end of their transition to practice. The sample size was determined by the ratio of 5-10 subjects per item as suggested by Everitt [ ]. To examine the test-retest reliability, another 60 students were recruited to test the PHCE scale and did it again after two weeks.

\section{Data analysis}

Descriptive statistics, such as mean and standard deviation, were used to report sample characteristics and the responses for the items on the PHCE. Exploratory factor analysis (EFA) was performed to examine the factor structure of the PHCE scale. Cronbach's alpha and item-to-total correlation were also used to examine the internal consistency of the scale, while intra-class correlation coefficient (ICC) was used to test the stability of the scale. A p-value of $<0.05$ was considered statistically significant. SPSS Version 20 was used to analyse the data (SPSS Inc., Chicago, IL, USA).

\section{Ethical considerations}

Approval for the study was obtained from the university research ethics committee. Before interviewing and conducting the survey, the researcher explained the purpose and nature of the study. Students were assured that their participation was voluntary and anonymous and that they could withdraw from the study at any time. The return of the questionnaire was considered their consent to participate in the study.

\section{Results}

\section{Sample characteristics}

Four hundred nursing students were recruited and invited to complete the questionnaire; 383 students returned the completed questionnaires, which resulted in a response rate of $95.75 \%$. The nursing students were aged $16-25$ years $($ mean $=21.00)$. The majority of them $(n=368,96.08 \%)$ were female. More than 
half of them ( $n=200,52.22 \%)$ were undergraduate nursing students, 137 (35.77\%) were diploma nursing students and $46(12.01 \%)$ were secondary nursing students.

\section{Factor structure}

Before performing the exploratory factor analysis (EFA), we conducted the Bartlett's test of sphericity and the Kaiser-Meyer-Olkin (KMO) measure. The Bartlett value was statically significant (X2囚1653囚 = $15370.706, p<0.001$ ), and the Kaiser-Meyer-Olkin measure of sampling adequacy was 0.961 , indicating that the assumptions were met to enable analysis of the 58-item PHCE through exploratory factor analysis with principal component and varimax rotation.

The initial principal component analysis (PCA) showed that all 58 items extracted a mine-factor solution for PHCE with eigenvalue $>1.0$. Varimax rotation indicated that one item loading was less than 0.4 , and 16 items were loaded equally under two factors. Hence, these 17 items were removed from the scale. A further EFA was performed with the remaining 41 items. Using PCA with eigenvalues $>1$, four factors were extracted from the remaining 41 items, which accounted for $63.69 \%$ of the variance. Figure 1 shows the scree plots illustrating the number of factors.

\section{Insert Fig.1 Scree plot for 41-item PHCE scale here}

The result of the rotated component matrix using varimax rotation is presented in Table 2. After removing the items with loading $<0.4$ or loading equally on two factors, 41 items showed strong factor loading from 0.481 to 0.804 . Factor 1 , clinical instructors' caring for patients, consists of seven items with item loading from 0.481 to 0.779 , accounting for $4.407 \%$ of the variance. Factor 2 , clinical instructors' caring for students, consists of 13 items with item loading from 0.635 to 0.768 , accounting for $11.210 \%$ of the variance. Factor 3 , caring from nursing peers, consists of 13 items with item loading from 0.612 to 0.804 , accounting for $42.692 \%$ of the variance. Factor 4 , caring from the other health care workers, consists of eight items with item loading from 0.648 to 0.763 , accounting for $5.383 \%$ of the variance. Therefore, this four-factor model represented the core subscales of the PHCE scale with a total of 41 items.

Insert Table 2 Rotated Component Matrixof Four Factors for PHCE (factor loading $>0.40$ are highlighted) $(n=383)$ here

\section{Insert Fig.1 Scree plot for 41-item PHCE scale here}

\section{Internal consistency and test-retest reliability}

Table 3 shows the results of inter-item consistency and test-retest of reliability. The Cronbach's alpha for the total scale was 0.98 , and each subscale of PHCE was $0.89,0.95,0.95,0.93$, respectively. The 
correlation coefficients between items and their own subscales ranged from 0.530 to 0.831 .

Sixty students were approached to attempt the PHCE scale again two weeks after the first questionnaire, of whom 42 students had valid results. The test-retest reliability was satisfactory with an ICC of 0.871 $(95 \% \mathrm{Cl}=0.759-0.931, p<0.001)$ for the total scale, and $0.78-0.87$ for the four subscales (Table 3$)$.

\section{Insert Table 3 Internal consistency and test-retest reliability}

\section{Discussion}

This study presented the development and psychometric evaluation of a culturally relevant 41-item PHCE scale in China. The development started by conducting a qualitative study to explore nursing students' perceptions of a caring clinical environment, which generated a comprehensive item pool. The four factors that emerged from the EFA reflected the four themes that emerged from the qualitative data. The nursing students value the caring behaviours of the clinical teachers toward their patients and families, which they could emulate during clinical practice. The factors also highlighted that a caring environment is facilitated when clinical teachers and other health care professionals show caring toward the students along with the importance of peer caring toward one another. Studies have shown the importance of listening to nursing students' accounts of their experiences, and of what they have observed from their clinical teachers, peers, patients and other health care workers [. In the study of first-year nursing students, it was found that caring was not what they expected [19]. However, nursing students learned from their experiences and vowed to provide caring behaviours toward their patients. Therefore, it is important that clinical teachers model caring behaviours not only to the patients and their families, but also to students $[19,24]$.

The results of the psychometric testing in our study indicated that the 41-item PHCE scale is a four-factor structure. The EFA showed good construct validity as each item was sufficiently loaded to its own domain with item loading of more than 0.40 []. In addition, the four factors had reached $63.693 \%$ of variance, indicating a good contribution of the variance of the four factors. The reliability analysis of the four factors and the total PHCE scale using Cronbach's alpha coefficients was greater than 0.80 , which suggested a satisfactory level of internal consistency reliability. The item-to-total correlations further affirmed the good internal consistency of the PHCE scale. In addition, the PHCE scale has good stability with satisfied test-retest reliability.

\section{Limitations Of The Study}

The use of convenience sampling may limit the generalisability of the results. Future studies with random sampling may add support to the validity and reliability of the instrument.

\section{Conclusions}


The role of nursing education is paramount for the acquisition and refinement of students' caring attributes [22]. When the teaching atmosphere is perceived as caring, nursing students []. Moreover, nursing is a practice-based profession, thus, the internship, which is the transition from theory to practice, would be the most important stage to form students' nursing values. Currently, there is no culture-specific caring tool to assess the hospital caring environment in mainland China. The results of this study showed that our newly developed 41 -item PHCE scale is a valid and reliable tool to assess nursing students' perceptions of caring in the clinical environment in China.

\section{Declarations}

\section{Abbreviation}

PHCE: Perceptions of Hospital Caring Environment; CVI: Content Validity Index; ICC: Intraclass Correlation Coefficient; EFA: Exploratory Factor Analysis; PCA: Principal Component Analysis.

\section{Ethics approval and consent to participate}

The study was approved by the research ethics committee of Hubei University of Medicine. The participants were informed of the purpose and nature of the study. They were assured that their participation was voluntary and anonymous and that they could withdraw from the study at anytime. The return of the questionnaire was considered as their consent to participate in the study.

\section{Consent to publish statement}

The authors give consent for this article to be published in BMC Medical Education.

\section{Availability of data and materials section}

The datasets supporting the conclusions of this article are included within the article. The questionnaires used and/or analyzed during the current study are available from the corresponding author on reasonable request.

\section{Competing Interest}

The authors declare that they have no competing interest

\section{Funding}

None. 


\section{Authors' contributions}

All the below authors have approved the final version of the article.

- CL has contributed to the: i) conception design of the study, ii) acquisition of data, iii) analysis and interpretation of the data, iv) drafting the article and v) critical revision of the article

- LYL has contributed to the: i) conception design of the study, ii) critical revision of the article.

- WW has contributed to the i) conception design of the study, ii) acquisition of data, iii) analysis and interpretation of the data and iv) critical revision of the article

\section{Acknowledgements}

The authors greatly appreciate the students, nurses and experts who supported the study.

\section{References}

1. . Willis DG, Grace PJ, Roy C. A central unifying focus for the discipline: Facilitating humanizing, meaning, choice, quality of life and healing in living and dying. Adv Nurs Sci. 2008;31(1):E28-E40.

2. . Allen D. Re-conceptualizing holism in the contemporary nursing mandate: From individual to organizational relationships. Soc Sci Med. 2014;119:131-138.

3. . Weinberg DD. When little things are big things. In: Nelson and S. Gordon, editors. The complexities of care: Nursing reconsidered . Ithaca, New York: ILR Cornell University Press; 2006. p. 30-43.

4. . Cook PR, Cullen JA. Caring as an imperative for nursing education. Nurs Educ Perspect. 2003;24(4):192-197.

5. . Roach S. Caring: The human act of caring: A Blueprint for the Health professions. Ottawa, Canada: Canadian Hospital Association Publications; 1987.

6. . Schoenhofer, SO. Infusing the nursing curriculum with literature on caring: an idea whose time has come. Int J Human Caring. 2001;5(2):7-14.

7. . Letcher, DC, Nelson ML. Creating a culture of caring: a partnership bundle. J Nurs Adm. 2014;44(3):175-186.

8. . Nursing AAOCO, Washington. The essentials of baccalaureate education for professional nursing practice. J Adv Nurs. 1998;34(6):724-725.

9. . Tanner CA. Caring as a value in nursing education. Nurs Outlook. 1990;38(2):70-72.

10. . Hughes LC, Kosowski MM, Grams K, Wilson C. Caring interactions among nursing students: a descriptive comparison of 2 associate degree nursing programs. Nurs Outlook. 1998;46(4):176-181.

11. . Simmons PR, Cavanaugh S. Relationships among childhood parental care, professional school climate, and nursing student caring ability. J Prof Nurs 1996;12(6):373-381. 
12. . Grams K, Kosowski M, Wilson C. Creating a caring community in nursing education. Nurse Educ. 1997;22(3):10-16.

13. . Cann L. Compassionate care for student nurses. Soins. 2016;805:53-55.

14. . Pai HC, Eng CJ, Ko HL. Effect of caring behavior on disposition toward critical thinking of nursing students. J Prof Nurs. 2013;29(6):423.

15. . Ma F, Zhu D. Survey on Caring Ability and Its Associated Factors among Baccalaureate nursing undergraduates. Chin J Evid-based Med (China). 2007;7(10):706-710.

16. . Huang GB, Xu L.Facing Challenge: Developing humanistic caring capability in collegiate nursing students. Chin Higher Med Educ (China). 2006;4:70-72.

17. . Chan DS. Validation of the clinical learning environment inventory. West J Nurs Res. 2003;25(5):519.

18. . Papastavrou E, Lambrinou E, Tsangari H, Saarikoski M, Leino-Kilpi H. Student nurses experience of learning in the clinical environment. Nurse Educ Pract. 2010;10(3):176-182.

19. . Phillips NM, Duke MM, Weerasuriya R. Questioning skills of clinical facilitators supporting undergraduate nursing students. J Clin Nurs. 2017;26(23-24):4344-4352.

20. . Hartup WW. The company they keep: friendships and their developmental significance. Child Dev. 1996;67(1):1-13.

21. . Beck CT. Caring among nursing students. Nurse Educator.1992;17(6):22.

22. . Beck CT. Caring relationships between nursing students and their patients. Nurse Educ 1993;18(5):28-32.

23. . Al-Kandari F, Vidal V L, Thomas D. Assessing clinical learning outcomes: a descriptive study of nursing students in Kuwait. Nurs Health Sci. 2009;11(3):252-262.

24. . Gustafsson M, Kullén E A, Ohlsson U, Sundler A J, Bisholt B. Nurse teacher models in clinical education from the perspective of student nurses-a mixed method study. Nurse Educ Today. 2015;35(12):1289-1294.

25. . Barry D, Houghton T, Warburton T. Supporting students in practice: leadership. Nurs Stand. 2016;31(4):46-53.

26. . Reuterswärd M, Hylander I. Shared responsibility: school nurses' experience of collaborating in school-based interprofessional teams. Scand J Caring Sci. 2017;31(2):253-262. doi:

$10.1111 /$ scs. 12337

27. . Loke JC, Lee KW, Lee B K, Mohd N A. Caring behaviours of student nurses: effects of pre-registration nursing education. Nurse Educ Pract. 2015;15(6):421-429.

28. . Polit D F, Beck CT, Owen SV. Is the CVI an acceptable indicator of content validity? appraisal and recommendations. Res Nurs Health. 2007;30(4):459-467.

29. . Everitt BS. Multivariate analysis: the need for data, and other problems. Br J Psychiatry. 1975;126(3):237-240. 
30. . Pearcey P, Draper P. Exploring clinical nursing experiences: listening to student nurses. Nurse Educ Today. 2008;28(5):595-601.

31. . Tabachnick BG, Fidell LS. Using multivariate statistics. 5th ed. Boston: Allyn and Bacon; 2007.

32. . Labrague LJ. Caring competencies of baccalaureate nursing students Samar State University. J Nurs Educ Pract. 2012, 2(4):105-113.

\section{Tables}

Table 1 58-item of PHCE 


\begin{tabular}{|c|c|}
\hline \multicolumn{2}{|c|}{ PART 1: The clinical teachers: } \\
\hline 1. & introduce themselves to patients when they first meet, \\
\hline 2. & explain procedure prior to initiation, \\
\hline 3. & protect patients' privacy, \\
\hline 4. & treat patients fairly, \\
\hline 5. & always smile and be kind and patient, \\
\hline 6. & talk with patients intentionally, \\
\hline 7. & answer quickly when patients call for them, \\
\hline 8. & explain in simple words, \\
\hline 9. & always encourage patients, \\
\hline 10. & hope to get support from the patients' families, \\
\hline 11. & encourage patients to share experiences, \\
\hline 12. & understand patients when they are angry, \\
\hline 13. & make patients physically or emotionally comfortable, \\
\hline 14. & check patients' conditions very closely, \\
\hline 15. & give treatments on time, \\
\hline 16. & explain preventive actions to patients and their families, and \\
\hline 17. & are grateful for patients' cooperation. \\
\hline \multicolumn{2}{|c|}{ PART 2: The clinical teachers: } \\
\hline 18. & sincerely want to see students succeed, \\
\hline 19. & praise students when they perform well, \\
\hline 20. & recognize when students have problems, \\
\hline 21. & believe students will do their best to take care of patients, \\
\hline 22. & listen to students' problems or concerns seriously, \\
\hline 23. & deal with students fairly, \\
\hline 24. & respect students' decisions, \\
\hline 25. & care about students' daily lives, \\
\hline 26. & give students reasons for decisions that affect them, \\
\hline 27. & encourage an open exchange of ideas among clinical instructors and students, \\
\hline 28. & tell students when they are doing something wrong and give them some advice, \\
\hline 29. & encourage students to state their ideas or opinions to the clinical instructors, \\
\hline 30. & take time to make sure students understand what they are learning, \\
\hline 31. & understand how it feels to be a student, \\
\hline 32. & do not make students feel stupid when asking questions, \\
\hline 33. & provide uplifting encouragement to their students, \\
\hline 34. & help students do a better job of taking care of patients, \\
\hline 35. & help students problem solve difficult patient situations, and \\
\hline 36. & tell students how to deal with relationships. \\
\hline \multicolumn{2}{|c|}{ PART 3: The students' peers: } \\
\hline & help fellow classmates with reasonable needs, \\
\hline & help classmates who encounter difficulties, \\
\hline 39. & are concerned about one another's health, \\
\hline 40. & accompany a classmate who is sick to get medical help, \\
\hline 41. & smooth things over when there is a conflict between classmates, \\
\hline 42. & give suggestions to a classmate who encounters difficulties with school assignments, \\
\hline 43. & encourage one another, \\
\hline 44. & provide company when a classmate is lonely, \\
\hline 45. & respect the different opinions of other classmates, \\
\hline 46. & listen to one another's troubles and problems, \\
\hline 47. & trust one another, \\
\hline 48. & talk to one another about problems, \\
\hline & share experiences and feelings in the patient setting, and \\
\hline 50. & share notes, books or articles with one another. \\
\hline
\end{tabular}

PART 4: The other health care workers: 
51. patiently answer students' questions,

52. help students with difficulties,

53. think students are learners, instead of people who do the chores,

54. tell students what their mistakes are, rather than laughing at or blaming them,

55. talk to students with a smile,

56. encourage students,

57. $\quad$ tell students their experiences, and

58. $\quad$ cooperate with students.

Table 2 Rotated Component Matrix of four factors for PHCE(factor loading $>0.40$ are highligted) $\square n=383 \square$ 
2.The clinical teachers explain procedure prior to initiation,

6.The clinical teachers talk with patients intentionally, .600 .300 .126 .188

9.The clinical teachers always encourage patients, .735 .303 .224 .124

10.The clinical teachers hope to get support from the patients' families, .779 .298 .142 .114

11.The clinical teachers encourage patients to share experiences, 757.178.099.204

12.The clinical teachers understand patients when they are angry, .653 .356 .206 .162

17.The clinical teachers are grateful for patients' cooperation, .679.274.113.205

21.The clinical teachers believe students will do their best to take care of patients,

.291 .635 .149 .182

22.The clinical teachers listen to students' problems or concerns seriously,

.195 .699 .191 .237

23.The clinical teachers deal with students fairly, .131 .767 .194 .228

24.The clinical teachers respect students' decisions, .158 .721 .157 .240

25.The clinical teachers care about students' daily lives, .202 .753 .217 .233

26.The clinical teachers give students reasons for decisions that affect them, .254 .684 .186 .245 27.The clinical teachers encourage an open exchange of ideas among clinical instructors and students,

28.The clinical teachers tell students when they are doing something wrong and give them some advice,

29.The clinical teachers encourage students to state their ideas or opinions to the clinical .267 .718 .131 .134 instructors,

30.The clinical teachers take time to make sure students understand what they are learning,

.177.768.161.186

31.The clinical teachers understand how it feels to be a student,

.237 .635 .195 .277

32.The clinical teachers do not make students feel stupid when asking questions, .263.673.188.270

34.The clinical teachers help students do a better job of taking care of patients, .234 .674 .248 .235

37.The students' peers help fellow classmates with reasonable needs, .160 .283 .612 .180

38.The students' peers help classmates who encounters difficulties, .148 .172 .737 .147

39.The students' peers are concerned about one another's health, .121 .132 .792 .152 40.The students' peers accompany a classmate who is sick to get medical help, .163 .168 .759 .115 41.The students' peers smooth things over when there is a conflict between classmates, .169 .118 .741 .087 42.The students' peers give suggestions to a classmate who encounters difficulties with .161 .118 .804 .073 school assignments,

43.The students' peers encourage one another,

.168 .113 .795 .103

44.The students' peers provide company when a classmate is lonely,

.167 .181 .774 .142

45.The students' peers respect the different opinions of other classmates,

.079 .164 .790 .189

46.The students' peers listen to one another's troubles and problems,

.102 .169 .762 .238

47.The students' peers trust one another,

.080 .165 .788 .240

48.The students' peers talk to one another about problems,

.035 .180 .736 .225

50.The students' peers share notes, books or articles with one another.

$-.098 .139 .650 .258$

51.The other health care workers patiently answer students' questions,

.121 .226 .277 .648

52.The other health care workers help students with difficulties,

.184 .236 .246 .682

53.The other health care workers think students are learners, instead of people who do the

.208 .215 .153 .679 chores,

54.The other health care workers tell students what their mistakes are, rather than laughing

.106 .362 .240 .655 at or blaming them,

55.The other health care workers talk to students with a smile,

.145 .288 .184 .763

56.The other health care workers encourage students, .155 .324 .283 .745

57.The other health care workers tell students their experiences, and

.205 .290 .275 .707 
Table 3 Internal consistency and test-retest reliability $(n=42)$ 
item

Cronbach's ICC item-total

alpha

correlation

factor 1:

$0.888 \quad 0.848$

2.The clinical teachers explain procedure prior to initiation,

0.530

6.The clinical teachers talk with patients intentionally,

0.607

9.The clinical teachers always encourage patients,

0.751

10.The clinical teachers hope to get support from the patients' families,

0.774

11.The clinical teachers encourage patients to share experiences,

0.697

12.The clinical teachers understand patients when they are angry,

0.727

17.The clinical teachers are grateful for patients' cooperation,

0.681

factor 2:

$0.953 \quad 0.869$

21.The clinical teachers believe students will do their best to take care of

0.693

patients,

22.The clinical teachers listen to students' problems or concerns seriously,

0.754

23.The clinical teachers deal with students fairly,

0.797

24.The clinical teachers respect students' decisions,

0.747

25.The clinical teachers care about students' daily lives,

0.816

26.The clinical teachers give students reasons for decisions that affect them,

0.763

27.The clinical teachers encourage an open exchange of ideas among clinical

0.752

instructors and students,

28.The clinical teachers tell students when they are doing something wrong

0.785

and give them some advice,

29.The clinical teachers encourage students to state their ideas or opinions to

0.744

the clinical instructors,

30.The clinical teachers take time to make sure students understand what they

0.775

are learning,

31.The clinical teachers understand how it feels to be a student,

0.730

32.The clinical teachers do not make students feel stupid when asking questions,

0.771

34.The clinical teachers help students do a better job of taking care of patients,

0.756

factor 3:

$0.952 \quad 0.779$

37.The students' peers help fellow classmates with reasonable needs,

0.667

38.The students' peers help classmates who encounters difficulties,

0.749

39.The students' peers are concerned about one another's health,

0.802

40.The students' peers accompany a classmate who is sick to get medical help,

0.759

41.The students' peers smooth things over when there is a conflict between

0.734

classmates,

42.The students' peers give suggestions to a classmate who encounters

0.786

difficulties with school assignments,

43.The students' peers encourage one another,

0.781

44.The students' peers provide company when a classmate is lonely,

0.789

45.The students' peers respect the different opinions of other classmates,

0.787

46.The students' peers listen to one another's troubles and problems,

0.793

47.The students' peers trust one another,

0.805

48.The students' peers talk to one another about problems,

0.759

50.The students' peers share notes, books or articles with one another. 
51.The other health care workers patiently answer students' questions,

52.The other health care workers help students with difficulties,

53.The other health care workers think students are learners, instead of people who do the chores,

54.The other health care workers tell students what their mistakes are, rather than laughing at or blaming them,

55.The other health care workers talk to students with a smile, 0.789

56.The other health care workers encourage students, 0.831

57.The other health care workers tell students their experiences, and 0.774

58.The other health care workers like to cooperate with students,

\section{Figures}

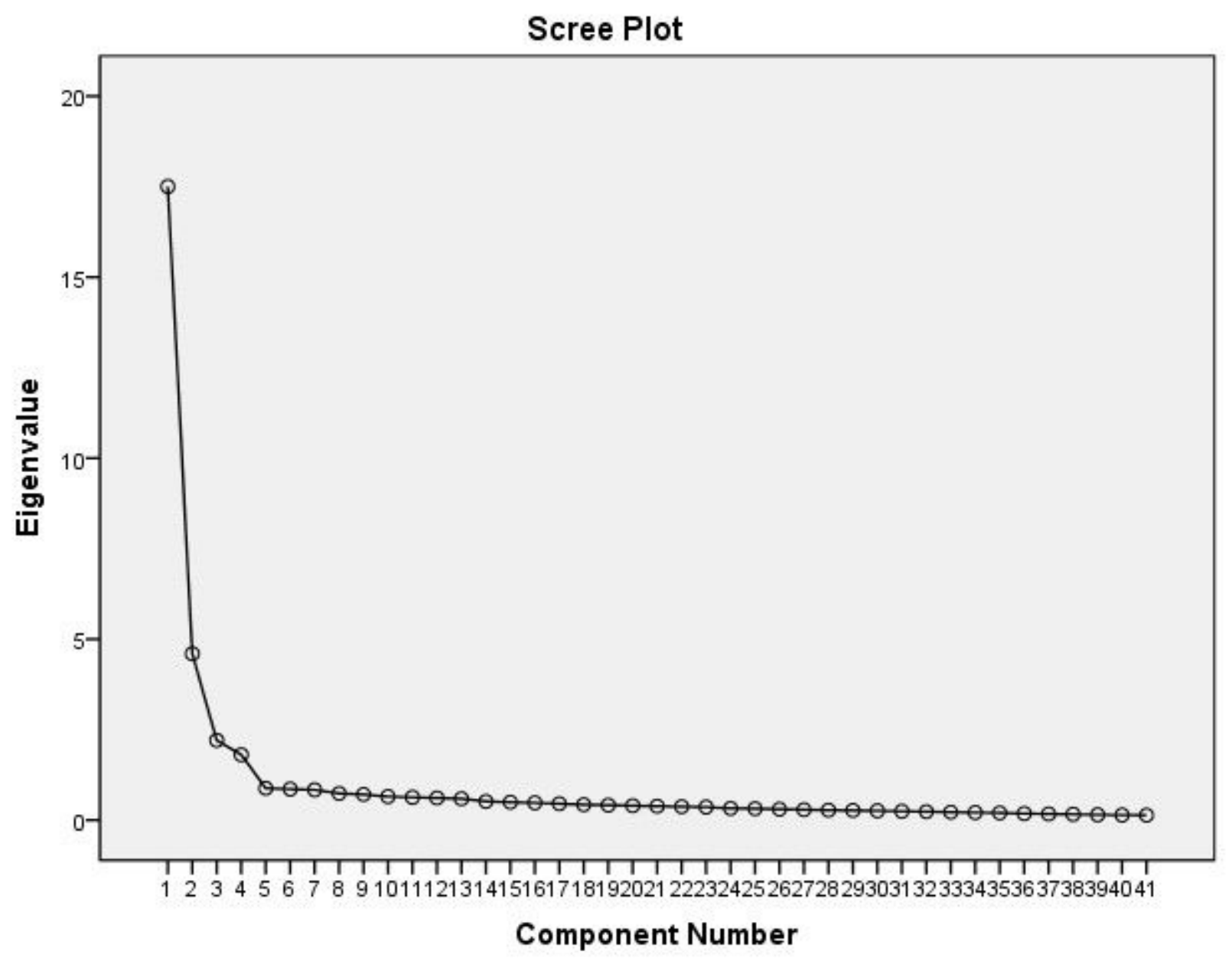

Figure 1 
